\title{
As escolas de referência em ensino médio de Pernambuco e a condição docente
}

\author{
Gomes, Danyella Jakelyne Lucas ${ }^{1}$ \\ Abranches, Ana de Fátima Pereira de Sousa²
}

\section{Resumo}

Este artigo apresenta um recorte dos resultados da pesquisa do curso de Mestrado que contempla as investigações em torno da temática da Educação Integral no Ensino Médio na rede estadual de Pernambuco e tem por objetivo analisar o Programa de Educação Integral de Pernambuco (PEI) que visa o desenvolvimento de políticas públicas direcionadas à melhoria da qualidade do ensino médio, tendo o professor no centro do processo pedagógico como um dos atores que contribuem efetivamente para a implementação da política nas Escolas de Referência em Ensino Médio - EREMs. Para tal, foram analisados os documentos referentes ao PEI e os que fundamentam a concepção do trabalho docente no Programa de Educação Integral e no interior das Escolas de Referência, bem como as formas e os critérios de acesso dos docentes no referido programa. Os resultados apontam que a implantação das Escolas de Referência do Ensino Médio em Pernambuco, implicou em discrepâncias no que diz respeito, sobretudo, ao atendimento e a garantia da permanência dos estudantes no programa/escolas bem como às condições do trabalho docente.

Ensino Médio. Educação Integral. Escolas de Referência em Ensino Médio.Docentes.

\section{Abstracto}

Este artículo presenta parte del curso principal de los resultados de búsqueda que incluyen investigaciones en torno al tema de la educación integral en la escuela secundaria en el sistema de estado de Pernambuco y tiene como objetivo analizar el Programa Integral de Educación de Pernambuco (PEI), destinado a el desarrollo de las políticas públicas destinadas a mejorar la calidad de la escuela secundaria, y la maestra en el centro del proceso educativo como uno de los actores que contribuyen eficazmente a la aplicación de la política en las Escuelas de Referencia en la Escuela Secundaria EREMs. Con este fin, se analizaron los documentos relacionados con el PEI y la concepción subyacente de la enseñanza en el Programa de Educación Integral y dentro de las Escuelas de Referencia, así como las formas y los criterios de acceso de los profesores en el programa. Los resultados muestran que la aplicación de las escuelas secundarias de Educación de referencia en Pernambuco, dio lugar a discrepancias con respecto a, por encima de todo, el servicio y la garantía permanente de los estudiantes en el programa / escuelas y las condiciones de la enseñanza.

1. Mestre em Educação, UFRPE/Fundaj. Analista em Gestão Educacional na SEE/PE $<$ danyellagomespe@hotmail.com>

2 Doutora em Educação Analista em Ciência e Tecnologia da Fundação Joaquim Nabuco/MEC Coordenadora do Mestrado Acadêmico em Educação, Culturas e Identidades Universidade Federal Rural de Pernambuco e Fundação Joaquim Nabuco. <pedagógico.ana.abranches@fundaj.gov.br> 
Escuela secundaria. Educación Integral. Escuelas de Referencia en la Escuela Secundaria. Profesores.

\section{Introdução}

O presente estudo é parte de uma pesquisa de mestrado que objetivou analisar as Escolas de Referência em Ensino Médio em Pernambuco e a realidade do trabalho docente nestas escolas, focando nas suas especificidades e transformações. As escolas de educação integral têm se transformado em uma realidade que cresce em vários estados e municípios, provocando impactos diversos no campo educacional, dentre eles a situação dos docentes, gerando interesse para pesquisas que buscam não só compreender tais impactos, bem como analisar o modo com que a educação, a partir desta nova realidade, vai se conformando na sociedade atual.

Desse modo é importante destacar a partir do contexto da aprovação da Lei Federal $n^{\circ}$ 13.005/2014, que dispõe sobre o Plano Nacional de Educação (PNE), e segundo os dados do Observatório do PNE, plataforma eletrônica que tem por objetivo monitorar os indicadores das metas do Plano Nacional da Educação, que cerca de 1,6 milhão de jovens, entre 14 e 17 anos, deveriam estar cursando o Ensino Médio. Do mesmo modo, o Plano prevê na Meta 6 Educação Integral a oferta de Educação em Tempo Integral em, no mínimo, 50\% das escolas públicas.

Até $2013,34,4 \%$ das escolas públicas do país ofertavam matrículas em tempo integral. Além do desafio de ampliar a oferta, há de se levar em conta a qualidade pedagógica da ampliação do tempo na escola a fim de que se evite a compreensão equivocada de que apenas com a ampliação do tempo se garanta a Educação Integral. Nesse sentido, a pesquisa delimita-se pelo viés qualitativo na perspectiva adotada por Triviños (2006), uma vez que não se sustenta apenas na informação estatística dada sua objetividade e uma validade conceitual que colaboram para o desenvolvimento do pensar cientificamente.

Para tal, a pesquisa foi realizada em duas Escolas de Referência localizadas na área de jurisdição da Gerência Regional Sertão do Moxotó Ipanema e Arcoverde. A análise foi realizada por meio da Abordagem do Ciclo 
de Políticas, formulada por Stephen Ball e Richard Bowe, uma vez que permite a análise processual considerando os contextos para implantação e implementação das políticas (MAINARDES, 2006), com destaque especial para o Contexto da Prática no qual a política está sujeita à interpretação dos atores.

Foram entrevistados 13 docentes que fazem parte do Programa de Educação Integral. As entrevistas foram analisadas por meio da técnica da Análise de Conteúdo (BARDIN, 1977) a fim de identificar os sentidos e significados atribuídos pelos atores acerca do que representa uma Escola de Referência em municípios de Pernambuco que possuem uma única escola de Ensino Médio.

A relevância do trabalho se dá devido à necessidade de compreender a política das Escolas de Referência em Pernambuco que visa à melhoria da qualidade da educação no Ensino Médio com ênfase no trabalho docente. Compreendemos que a Educação Integral e em tempo integral está para além da ampliação do tempo de permanência diária dos estudantes na escola.

1 Programa de Educação Integral: criação e expansão das Escolas de Referência em Ensino Médio em Pernambuco (2000-2014)

Em Pernambuco, as experiências em torno da Educação Integral ganharam destaque a partir do ano 2000, através do projeto piloto do Centro de Ensino Experimental Ginásio Pernambucano (CEEGP) e do Programa de Desenvolvimento dos Centros de Ensino Experimental (Procentro). O projeto CEEGP surgiu da proposta, primeiramente, de revitalização do edifício no qual está o Ginásio Pernambucano ${ }^{3}$, instituição tradicional e de grande importância histórica para o Estado, que se encontrava deteriorada e, em segundo lugar, visava à recuperação da qualidade do ensino através da criação de um novo modelo de escolas para a educação pública. A busca por uma nova escola pública de Ensino Médio em tempo integral capaz de conciliar a universalização com a qualidade baseada em uma pedagogia eficaz e numa gestão

${ }^{3}$ O Ginásio Pernambucano é umas das escolas secundárias mais antigas do Brasil e funcionou como regime de internato ainda no período de 1855 , sendo a experiência pioneira em educação integral em Pernambuco (HENRY, 2008). 
comprometida com resultados pautava o discurso governamental da época. Inicialmente, o CEEGP foi introduzido como projeto piloto estabelecido por meio de parceria público-privada, uma das características do modelo adotado, colocando em dúvida a própria capacidade do Estado em fornecer condições para sua implementação.

Em 2004, com a criação do Programa de Desenvolvimento dos Centros de Ensino Experimental - Procentro, o projeto piloto passou por um processo de ampliação no qual foram estabelecidos os critérios para criação dos centros nas demais cidades, bem como regulamentava as formas de acesso - para estudantes e docentes, de gestão, sistema de avaliação, acompanhamento escolar e de desempenho e bonificação dos centros. A implementação do programa teve forte resistência em várias instâncias da sociedade, sobretudo pelas entidades de classe que alegavam ser este o passo inicial para a privatização da educação pública em Pernambuco.

O processo de expansão do modelo de educação integral culminou com a criação do Programa de Educação Integral - PEI, normatizado por meio da Lei Complementar Estadual no 125/2008. Atualmente, o PEI tem por objetivo o desenvolvimento de políticas públicas direcionadas à melhoria da qualidade do ensino médio e à qualificação profissional dos estudantes da Rede Pública Estadual; e por finalidade, dentre outras, difundir o modelo de educação integral no Estado, com foco na interiorização das ações e na adequação da capacitação da mão de obra, conforme características econômicas da região.

As Escolas de Referência em Ensino Médio (EREMs) são o meio pelo qual a política de educação integral se materializa e chega à população em Pernambuco. A legislação que cria e regulamenta o $\mathrm{PEI}$ define os critérios para a implantação das EREMs, levando em consideração os padrões mínimos estabelecidos como infraestrutura, equipamentos, remuneração dos docentes e carga horária, dentre outros. Em relação ao funcionamento, a característica principal das EREMs é a ampliação da carga horária das escolas que se dá da seguinte maneira: as escolas de jornada semi-integral, com carga horária de 32 horas/aula semanais, distribuídas em 05 (cinco) dias por semana durante o turno da manhã, sendo que em 02 (dois) dias os estudantes têm aulas nos dois turnos; 
e as escolas com jornada integral, com carga horária de 40 horas/aula semanais, distribuídas em 05 (cinco) dias por semana durante os dois turnos.

Com a ampliação da jornada, o currículo e os espaços pedagógicos das escolas são reconfigurados para atender à demanda de uma formação integral e em tempo integral. A ampliação da jornada escolar implica em uma reestruturação das bases curriculares que precisam ser pensadas de forma a tornar não apenas os espaços, mas também os tempos pedagógicos adequados ao novo modelo.

Embora a expansão da educação integral seja um caminho para a universalização de uma educação de qualidade, há de se levar em conta o contexto e a maneira como o processo vem ocorrendo de modo a proceder a uma reflexão sobre os impactos que essas transformações acarretam para a população dos municípios e para a vida escolar dos próprios estudantes, bem como dos docentes.

\section{Uma escola em tempo integral em cada município de Pernambuco até 2014: a quem serve essa meta?}

Em entrevista veiculada pelo site "Ação Educativa", no dia 07/12/2011, o Secretário-executivo de Educação Profissional afirma que a meta da Secretaria de Educação é atingir um número de 300 Escolas de Referência em todo o Estado, com pelo menos uma escola desta modalidade - integral ou semiintegral - em cada município tendo projeção de alcance de aproximadamente $80 \%$ dos alunos da rede até 2014. Tal meta faz parte das ações do Pacto pela Educação 4 lançado pelo governo estadual em 2011. As diretrizes do Pacto estabelecem que, com a ampliação, todas as escolas que oferecem o ensino médio no estado passam a ser monitoradas pelo programa através de indicadores de processo e resultado, sendo priorizadas as que possuem ensino

\footnotetext{
${ }^{4}$ O Pacto pela Educação faz parte do Programa Governo Presente e configura-se numa política de controle e monitoramento das ações na área de educação, assim como ocorre com o Pacto pela Vida que se destina ao monitoramento do setor de segurança pública. O objetivo do Pacto é garantir educação pública de qualidade e formação profissional.
} 
médio, sejam ou se tornem escolas de referência ou técnica até 2014, e as escolas que não evoluíram no Idepe 52010.

A escola de tempo integral geralmente é instalada em um prédio no qual já funcionava uma escola de ensino médio regular, sendo que para isso se fazem necessárias adaptações na estrutura física para o funcionamento do "novo modelo". Segundo informações disponibilizadas no site da Secretaria de Educação, compõe o quadro de Escolas de Referência um total de 300 unidades escolares, sendo 125 funcionando em jornada integral e 175 em jornada semiintegral, atingindo assim a meta projetada pelo governo estadual de 01 Escola de Referência em cada município do estado. Tal indicador evidencia uma ampliação muita mais quantitativa do que qualitativa, uma vez que a maioria das escolas transformadas em EREMs funciona em jornada semi-integral. A precariedade no processo de expansão já era sinalizada por Morais (2013) como desigual em função das disparidades existentes entre as escolas do próprio programa implicando na existência de escolas diferentes dentro da própria rede de ensino:

No entanto, a expansão precária e desigual é comunicada como transitória, demonstrando a utilização desse discurso mais uma vez criando uma ilusão de que em Pernambuco há um novo modelo de Escola sendo construído. Se essa desigualdade acontece entre as Escolas do mesmo Programa observemos as disparidades entre as EREMs e as Escolas de Ensino Médio da rede considerando a diferença do custo aluno entre elas.(p. 125).

Cabe chamar a atenção sobre o impacto da meta projetada para os estudantes de ensino médio dos municípios de Pernambuco onde só existe uma escola de ensino médio de referência. Em 2013, havia 133 municípios com uma Escola de Referência para o Ensino Médio. Destas, 65 escolas são de regime semi-integral e 68 são de tempo integral. (PERNAMBUCO, 2013).

No caso dos municípios onde só existe uma escola que oferece o ensino médio evidencia-se que não há obrigatoriedade de os estudantes do Ensino

\footnotetext{
5 Índice de Desenvolvimento da Educação de Pernambuco - permite medir anualmente a qualidade da educação de Pernambuco. <www.siepe.educacao.pe.gov.br>
} 
Médio cursarem o tempo integral nas Escolas de Referência. Entretanto, o tempo integral é a única opção para essas escolas que são as únicas a oferecerem o Ensino Médio nos municípios analisados. De uma maneira geral, a "obrigatoriedade" não está expressa nos documentos legais que normatizam o funcionamento das EREMs, porém acaba se configurando devido à falta de opção para o acesso dos estudantes ao Ensino Médio.

Dessa forma, o Programa de Educação Integral exclui do processo os alunos trabalhadores, reduz o número de matrículas, exclui os "excedentes" daquela Unidade Escolar que, neste caso, é única no município e diante da situação o programa não prevê nenhuma alternativa de incentivo à permanência dos estudantes que não podem aderir ao novo formato de escola.

\section{Os docentes das e nas Escolas de Referência em Ensino Médio: Referência para quem?}

A política passa por um processo de recontextualização em função dos que a executam, nesse caso os docentes, e, baseados em suas diferentes experiências, crenças e valores, a interpretam de diversas formas. Nesse aspecto, Ball e Maguire (2007, p. 99) apontam que:

a lógica embutida na abordagem norte-americana é que uma maior efetividade é atingida quando se é capaz de envolver os professores no processo decisório. A crença de que a participação do professor na mudança e seu comprometimento com essa mesma mudança e as habilidades e insights que eles trazem e desenvolvem contribuirão para uma efetiva reestruturação é, sem sombra de dúvida, fundamental para o desenvolvimento da escola nos EUA.

Além disso, Ball (2005) discorre acerca de três das principais tecnologias presentes nas reformas educacionais: o profissionalismo, o gerencialismo e a performatividade que, se utilizadas em conjunto, se apresentam como uma alternativa eficaz ao modelo de gestão tradicional centralizado no Estado. Para o autor, a utilização das tecnologias na administração do serviço público no contexto das reformas educacionais implica na implantação de técnicas e artefatos que visam organizar as forças humanas e as capacidades de poder. 
O profissionalismo emerge das mudanças que ocorrem nas forças que condicionam a relação subjetiva entre o profissional e o seu trabalho, em uma relação de compromisso, no qual só tem sentido dentro de parâmetros de racionalidade substantiva. Segundo Ball (2005), o profissionalismo só se sustenta dentro de uma reflexão moral e do diálogo uma vez que, na ausência desses elementos, tal tecnologia deixa de existir.

Do mesmo modo, o gerencialismo é uma das principais tecnologias políticas nas reformas educacionais. É uma forma de poder, ou mesmo, um instrumento, que se apresenta no setor público estabelecendo uma cultura de competitividade nas e entre as instituições. Para Ball (2005, p. 38), "o gerenciamento trabalha para incutir performatividade na alma do funcionário. Isto tem sido o principal meio pelo qual a estrutura e cultura dos serviços públicos são reformulados".

Por fim, a tecnologia da performatividade envolve "as performances de indivíduos ou organizações, servem como medidas de produtividade ou resultado, demonstrações de "qualidade", ou "momentos" de promoção ou inspeção" (BALL, 2012, p. 37). A performatividade se utiliza de mecanismos de controle que servem para estimular, comparar os resultados de instituições e sujeitos. Nessa tecnologia, a performatividade envolve os profissionais para 0 cumprimento de metas.

Dessa forma, a organização do trabalho pedagógico no interior das EREMs é um dos indícios de que a reestruturação pela qual a rede de ensino de Pernambuco vem passando ao longo dos últimos anos coloca o docente no centro do processo pedagógico como um dos atores que contribuem efetivamente para a implementação da política. É nas escolas que a política está sujeita à interpretação e à recriação por ser o local no qual os efeitos e as consequências se apresentam. É nela que as mudanças e transformações do texto político se evidenciam.

Nesse sentido, apresentamos um perfil dos docentes que atuam nas escolas analisadas, sendo denominadas EREM 1 e EREM 2, no quadro a seguir:

\section{Quadro 1 - Perfil dos docentes das EREMs}




\begin{tabular}{|l|c|c|}
\hline \multicolumn{1}{|c|}{ Aspectos do Perfil } & EREM 1 & EREM 2 \\
\hline Docentes entrevistados (Quadro Efetivo) & 05 & 08 \\
\hline Idade (em média) & 50 anos & 47 anos \\
\hline Tempo de Serviço (em média) & 25 anos & 17 anos \\
\hline Tempo de Lotação na Escola (em média) & 18 anos & 10 anos \\
\hline Tempo de Formação na graduação (em média) & 22 anos & 22 anos \\
\hline
\end{tabular}

No que diz respeito à formação continuada, todos os entrevistados possuem pós-graduação em nível lato sensu na sua área de atuação e integram o quadro de docentes efetivos da rede estadual de ensino com média de 03 (três) anos de lotação no Programa de Educação Integral. Para integrar o quadro de docentes das Escolas de Referência, participaram de processo seletivo composto de três etapas: 1) Análise de currículo; 2) Prova escrita de conhecimentos voltados à prática pedagógica; 3) Entrevista dos inscritos com técnicos vinculados ao $\mathrm{PEI}$.

Atuam na regência de aulas dos componentes curriculares de Língua Portuguesa, Matemática, Física, Biologia, Química, Filosofia, Geografia, Sociologia e Direitos Humanos. Vale ressaltar que a carga horária média de trabalho mensal dos docentes varia de $200 \mathrm{~h} / \mathrm{a}$ à $350 \mathrm{~h} / \mathrm{a}$, uma vez que cerca de $55 \%$ possuem mais de um tipo de vínculo de trabalho ${ }^{6}$, geralmente acumulado nas redes municipais de ensino.

Do universo analisado, outro dado que chama a atenção é que do processo seletivo participam apenas os docentes com vínculo de trabalho efetivo. Entretanto, aproximadamente $78 \%$ dos docentes de ambas as escolas atuam com vínculo de trabalho temporário. Tal condição reforça a existência de duas realidades no que diz respeito ao atendimento ao docente: por um lado, os efetivos, que em ambas as escolas são a minoria, passam por processo seletivo para compor o grupo seletivo de "docentes de referência", tendo sua rotina de trabalho alterada em função da ampliação da jornada que também altera a remuneração. Por outro lado, os docentes contratados assumem as vagas que

\footnotetext{
${ }^{6}$ A proposta do Programa de Educação Integral é que os professores atuem nas Escolas de Referência em regime de dedicação exclusiva, justificando assim a ampliação da jornada de trabalho e a gratificação de localização. Entretanto, alguns professores mantêm outros vínculos de trabalho com as redes municipais trabalhando no turno noturno.
} 
não são preenchidas pelos docentes efetivos e também atuam nas EREMs atendendo às mesmas exigências.

A pesquisa aponta que, para $51 \%$ dos docentes, a gratificação é um dos atrativos e fica condicionada à aprovação no processo seletivo, uma vez que a remuneração fica diretamente associada ao regime de funcionamento da escola - semi-integral ou integral. O valor da gratificação por localização no Programa de Educação Integral varia de acordo com a jornada das EREMs: "para os docentes com carga horária de até 32 horas/aula, a remuneração é de 159\%; e de $199 \%$ para a jornada de até 40 horas/aula do salário base" .(PERNAMBUCO, 2008).

No que tange à melhoria da remuneração dos docentes, convém salientar que esta se dá durante o período que o docente fica lotado no PEI, uma vez que, em caso de afastamento - para cursos, licenças ou aposentadoria, por exemplo -, os docentes perdem o direito à gratificação. Além disso, os docentes com vínculo temporário não recebem a gratificação de localização como os docentes efetivos recebem. Porém, estão submetidos às mesmas cobranças em função de um mesmo objetivo: implementar a meta de uma Escola de Referência em cada município.

Nesse sentido, a condição para o recebimento é estar em efetivo exercício de sala de aula o que vem sendo alvo de críticas pelos próprios profissionais bem como pelas entidades de classe tendo em vista que, com o "novo modelo" de escola, acaba sendo criado mecanismos de controle e de distinção, sobretudo em relação aos vínculos de trabalho, pois nem todos os docentes, assim como os estudantes, optam por fazerem parte do Programa. Desenha-se uma discrepância dentro da própria rede estadual chegando a ser injusta, uma vez que duas realidades se apresentam na qual os docentes recebem tratamentos distintos em função do tipo de vínculo trabalhista.

Percebemos que, conforme apontado por Ball (2005), no contexto das reformas educacionais, o termo profissionalismo passa por um processo de ressignificação nos textos gerenciais, de modo que, ao profissional, cabe apenas a responsabilidade por seu desempenho. Porém, o profissional fica alheio ao 
julgamento de seu desempenho, uma vez que esse se dá em função de satisfazer ou não aos critérios que se espera atingir.

Do mesmo modo, Gaulejac (2007, p. 90) define desempenho como "medida dos resultados obtidos por um indivíduo, uma equipe, uma organização ou um processo. Ela é a finalidade suprema". Para o autor, é conveniente que o bom desempenho perpasse todos os registros, cada uma das atividades e as funções da organização.

De uma maneira geral, percebemos na análise dos dados que os docentes estão inseridos na cultura do gerencialismo e a tecnologia da performatividade se evidencia na medida em que todo o fazer pedagógico é traduzido em números, em metas a serem perseguidas e, consequentemente, alcançadas. Mesmo sem um direcionamento claro buscam constantemente interpretar a política posta nos documentos oficiais e a reinterpretam na prática cotidiana.

\begin{abstract}
Em termos gerais, os professores acabam inseridos na performatividade pelo empenho com que tentam corresponder aos novos (e às vezes inconciliáveis) imperativos da competição e do cumprimento de metas. Os compromissos humanísticos do verdadeiro profissional - a ética do serviço - são substituídos pela teleológica promiscuidade do profissional técnico - o gerente. A eficácia prevalece sobre a ética; a ordem, sobre a ambivalência. Essa mudança na consciência e na identidade do professor apoia-se e se ramifica pela introdução, na preparação do professor, de formas novas de treinamento não intelectualizado, baseado na competência. (BALL, 2005, p. 548).
\end{abstract}

A tecnologia da performatividade, associada ao gerencialismo, acaba remodelando a prática do docente, até mesmo em sala de aula, e todo o foco do trabalho docente passa a ser direcionado para a obtenção de resultados. Nesse sentido, fica evidente nas entrevistas que os docentes que compõem o universo das escolas modelo são impactados com a introdução dessas tecnologias no cotidiano escolar. 


\section{Considerações Finais}

O Programa de Educação Integral é uma política que vem alterando profundamente a dinâmica da rede de ensino com implicações diretas no trabalho docente e requer, por parte da comunidade escolar, uma melhor compreensão da política e da proposta em sentido mais amplo uma vez que passa por um período de ressignificação do trabalho pedagógico para atender não apenas às alterações advindas com a ampliação da jornada, bem como pelas necessidades da sociedade atual também em transformação.

Nas Escolas de Referência o trabalho docente acaba sendo reconfigurado em função das metas que são estabelecidas e que devem ser perseguidas incessantemente. A conquista de tais metas é que define qual o nível de qualidade dessas escolas e reforçam que a educação que se faz nelas é (ou não) de qualidade, é (ou não) de Referência.

Esta busca por resultados, por vezes, pode implicar em uma competitividade entre as escolas dentro da mesma rede, característica da cultura da performatividade, onde o que importa é o desempenho do docente para o alcance desses resultados.

Neste contexto, as análises evidenciam o caráter seletivo adotado pelas Escolas de Referência para com os docentes: se, para compor o quadro das EREMs, os docentes efetivos passam por um processo seletivo que implica, indiretamente, na alteração da jornada de trabalho e na remuneração, como pode o docente com vínculo de trabalho temporário tornar-se docente de "Escola de Referência" sem ter o mesmo tratamento? Observar-se que o trabalho do docente contratado temporariamente possui as mesmas cobranças e demandas do docente com vínculo permanente, mas remuneração diferenciada. Constatando assim que dentro da mesma rede e da mesma escola são produzidas contradições e desigualdades. $O$ que nos leva a formular a seguinte questão: As escolas são de referência para quem e para quê?

Convém ressaltar a marcante ausência das vozes dos atores - docente, estudantes e pais, no que concerne à implantação e implementação da política, o que os coloca na condição de meros receptores. As Escolas de Referência 
chegam aos municípios sem consulta ou informações prévias sobre sua importância, finalidade e sobre possíveis ajustes para atender as especificidades da realidade local.

As análises dos dados evidenciam que aproximadamente $78 \%$ dos docentes das escolas pesquisadas atuam com vínculo de trabalho temporário. Corroborando a existência de duas realidades da condição docente nas escolas de referência em Ensino Médio em Pernambuco.

Desse modo, entendemos que a implantação das Escolas de Referência do Ensino Médio em Pernambuco, à medida que se apresenta como um avanço que permitiu a igualdade de condições do jovem estudante do Ensino Médio para o acesso às Universidades ou ao mercado de trabalho implicou em discrepâncias no que diz respeito, sobretudo, ao atendimento e a garantia da permanência dos estudantes no programa/escolas bem como às condições do trabalho docente.

A Educação Integral não pode ser entendida apenas em função da ampliação dos tempos escolares, mas, sobretudo, em função dos sujeitos envolvidos a fim de que se favoreça uma educação de qualidade, enquanto dimensão de desenvolvimento integral constituindo a articulação dos saberes em um campo plural.

\section{Referências}

BALL, S. Profissionalismo, Gerencialismo e Performatividade. Cadernos de Pesquisa, São Paulo, v. 5, n. 126, p. 539-564, set./dez. 2005.

Reforma educacional como barbárie social: economismo e o fim da autenticidade. Práxis Educativa, Ponta Grossa, v. 7, n. 1, p. 33-52, jan./jun. 2012. ; MAGUIRE, M. Discursos da Reforma Educacional no Reino Unido e Estados Unidos e o trabalho dos professores. Práxis Educativa, Ponta Grossa, v. 2, n. 2, p. 97 - 104, jul.-dez. 2007.

BARDIN, L. Análise de conteúdo. Lisboa: Edições 70, 1977.

EM Pernambuco, as escolas de referência existem desde 2004. Disponível em: http://www.acaoeducativa.org.br/index.php/juventude/40-juventude-etrabalho/10004237-em-pernambuco-escolas-de-referencia-de-ensino-medio-existemdesde-2004. Acesso em: 25 maio 2014.

GAULEJAC, V. Gestão como doença social: Ideologia, poder gerencialista e fragmentação social. Aparecida, SP: Ideias \& Letras, 2007.

HENRY, R. Ginásio Pernambucano: os desafios para transformar um projeto piloto de sucesso em política educacional. Recife: Ed. Universitária da UFPE, 2008. 
MAINARDES, J. Abordagem do Ciclo de Políticas: uma contribuição para a análise de políticas educacionais. Educação e Sociedade. Campinas. v. 27, n. 24, p. 47-69, jan/abr. 2006. Disponível em: <http://www.scielo.br/pdf/es/v27n94/a03v27n94.pdf> Acesso em: 22 jun. 2015.

MORAIS, E. V. Utilizações das Escolas de Referência em Ensino Médio pelo governo do estado de Pernambuco: uma análise do Programa de Educação Integral. Caruaru: UFPE/CAA, 2013.

PERNAMBUCO. Lei Estadual Complementar no 125, de 10 de julho de 2008. Dispõe sobre a criação do Programa de Educação Integral. Diário Oficial de Pernambuco de 11 de jul. 2008. Recife, 2008.

Secretaria de Educação. Balanço das Ações 2013. Secretaria de Educação do Estado de Pernambuco. Recife, 2013.

TRIVIÑOS, A. N. S. Introdução à pesquisa em ciências sociais: a pesquisa qualitativa em educação. São Paulo: Atlas, 2006. 